\title{
DRIVERS AND MODERATORS OF BUSINESS DECLINE
}

\author{
Marius Pretorius - Department of Business Management, University of Pretoria
}

\begin{abstract}
Purpose: Reports of business failure elicit various reactions, while research in this domain often appears to be limited by a lack of access to information about failure and by the negativity that surrounds it. Those who have experienced failure do not readily talk about it, or they disappear from the radar screen of researchers. Yet failure is preceded by decline which, when focused on strategically, can reduce eventual failures if early action is taken. The main purpose of this study is to develop a conceptual framework or typology of the drivers and moderators of business decline.
\end{abstract}

Design/methodology/approach: After applying the "grounded theory" approach to the academic literature on decline and failure, a conceptual framework for the variables that drive and moderate business decline is proposed.

Findings: The study proposes that decline has three core drivers, three peripheral drivers and four moderators. The core drivers identified are: resource munificence; leadership as origin; and causality (strategic versus operational origin of decline). The three peripheral drivers are: unique preconditions; continuous decisions impact; and extremes dichotomy. The study describes four moderators of the drivers: life cycle stage; stakeholder perspective; quantitative versus qualitative nature of signs and causes; and finally the age and size effects.

Research limitations/implications: The proposed conceptual framework is based on literature only, although it has found support during discussions with practitioners. It is proposed to readers of this journal for scrutiny and validation.

Practical implications: Strategists need to understand what drives decline in order to act timeously; practitioners who have an insight into the moderators with their impacts could make better decisions in response to decline in organisations and possibly avoid business failure.

Originality/Value: Understanding business decline is still a huge theoretical challenge, which drives turnaround strategies chosen by management. The proposed conceptual framework has this as its focus.

Key words: Decline, failure, business, trouble, crisis, decision making

\section{INTRODUCTION}

We know that businesses fail, as such failures attract media attention on a regular basis. Failure is financially costly to firms and owners (Shepherd, Wicklund \& Haynie, 2007:1). For many years it has been acknowledged that the analysis of failure in business is important to counter business risk and improve indications of success. Icons like Enron and Worldcom were not spared eventual failure; their declines have dominated reports of crises in the media in recent times, and led to investors losing major assets. The potential consequences of failure have significant and interesting impacts on business decisions. Crutzen \& Van Caillie (2007:2) postulate that business failure has been one of the most investigated topics of the last seven decades.

Existing writings about failure-related issues diverge into several fields; many different approaches to failure research exist, with several overlapping fields making up the domain (Crutzen \& Van Caillie, 2007:3). Existing research also has limitations, partly because of the current definition of failure and the way failure has been measured in the past (De Castro et al, 1997:1).

While failures, whether in start-up or mature businesses, attract attention all the time, decline is not so visible and therefore receives little attention in the media. Understanding business decline is still a huge theoretical challenge that drives the turnaround strategies that managers choose. Learning from the failure experience is critical for it to serve as a positive feedback mechanism (Shepherd, 2003:318) and improve strategy making to cope with future declines. Yet Ooghe and de Prijcker (2008:224) suggest that an all-embracing research approach that relates causes of failure (bankruptcy) to financial symptoms of distress has never been applied. That such a challenge has largely gone unanswered is relatively easily understood (Cybinski, 2001:39; Shepherd, 2005:126).

Judging by the research literature (Pretorius, 2008a:408), it appears that decline is an inherent part of the science of business management. If decline precedes failure, as suggested, it is of strategic importance to the venture for managers to understand the drivers of decline. Despite many scientific reports on decline, reports on the driving forces of the phenomenon are fragmented, and to some extent suffer from author bias. This study therefore aims to identify, through grounded theory research of the literature, the 
core and peripheral drivers (driving forces) and the moderators of the decline phenomenon. It proposes a framework of these drivers and describes the variables that would influence how these drivers are manifested. Both drivers and moderators are critical for strategy formulation.

Decline appears to be a natural step in the life-cycle process and may lead to failure of ventures based on the "survival of the fittest". This suggests that the drivers of decline respond to environmental factors and may even be moderated by several other factors. These drivers and moderators of the decline process are the focus of this study.

\section{AIM OF THIS STUDY}

There is a limited but growing body of knowledge on the topic of business decline for researchers to base their investigations on, especially in the small business domain. The research articles appear to be scattered between business, management, financial, psychology, entrepreneurial and other literature and no proof could be found that this work has ever been comprehensively reviewed.

The aim of this study is therefore to identify the drivers of decline and the variables that may moderate how these drivers are manifested, depending on the moderators. Achieving this goal would confirm or challenge conventional wisdom on decline and failure, and create a research agenda that identifies avenues for extending research in this area. Entrepreneurs, business decision makers, trainers, practitioners and advisers could benefit, as the proposed framework gives directions for areas to focus on during decline and the selection of strategies in response.

This study is also relevant and timely in view of the general recessionary conditions following the aftereffects of the sub-prime crisis. The rapid changes that impact on decline in business call for all possible assistance to contextual understanding.

Metaphorically, this study follows the physical law based on white light that is projected through a glass prism and results in refractive colours. In the same way a sharp light shone on "decline" will help us to find new insights when the light is seen from the alternative angles. This study therefore attempts to consolidate and strengthen the theoretical basis of business decline by systematically integrating the findings of existing studies to produce the framework. The objective is to develop an account of the main drivers and moderators of business decline.

\section{METHOD OF REVIEW}

The specific research need identified in this article is one of better understanding and sense making rather than prediction of failure, although the two focuses are related and many recent published works have been in the field of failure prediction, as reported by Sharma (2001:5). The methodology was selected because primary sources of decline are limited; failed firms disappear and entrepreneurs of failed ventures rarely like to talk about the reasons for the failure. If they do speak out, such explanations are likely to have self-reporting and retrospective reporting biases (Shepherd, 2005:126).

Academic resources from the ABI-Inform, Ebsco-host, Proquest, Blackwell and other databases were searched for titles published since 1985. The date was somewhat arbitrarily determined (and not necessarily adhered to) on the basis of convenience, as this was the earliest date for which most databases had downloadable electronic titles, abstracts and full texts readily available. For apparently major works, the date was not a limitation, especially when an article was referenced widely. Age of publication was not considered important, but quality and contribution to the body of knowledge of failure were paramount.

At first I searched for "failure" combined with "business", "venture", "firm" or "organisation". All searches were keyword-based searches that were narrowed down by using the different keyword variants identified during the process. At this junction it is stated that in this study terms such as firm, business, venture and organisation are interchangeably used, depending on the referenced author's choices.

As the articles (data) were obtained, searches were extended to include terms such as crisis, decline, discontinuance, distress and others as search terms/concepts. All articles were scanned on the basis of titles and abstracts, followed by a first complete reading of each article that was deemed to cover failurerelated issues, in a way similar to that described by Forbes (1999:417) when classifying the literature on cognitive biases of entrepreneurs. When "prediction" was used in conjunction with failure, a plethora of articles were found in a range of financial and accounting journals and it was clear even at this early 
juncture that failure prediction (as the financial perspective) made up the largest part of the total research base associated with failure. Balcaen \& Ooghe $(2005: 24)$ suggest that corporate failure prediction has become a major research domain within corporate finance.

Second and third rounds of searches were conducted using author names in addition to keywords for cross-referencing. Thereafter specific journals were searched one by one. Key journals included the Journal of Business Venturing, Entrepreneurship Theory and Practice, Academy of Management Review, Sloan's Management, Academy of Management Executive, British Journal of Management, Administrative Science Quarterly, Long Range Planning, Strategic Management Review, The British Accounting Review, Organisational Science and the Journal of Small Business Management, but were not limited to these. References of important articles were then searched and accessed to build up an extensive list of articles.

At first the definitions of failure were mapped and the definitions of decline and failure were investigated through a "snowball" process, but these are not reported in this study. Articles covering all failure-related terms were investigated to identify more references. These articles were then obtained and the process repeated to identify the key works referenced by the different authors. Borrowing from Corbin and Strauss's (1990) method on grounded theory research, concepts for each definition were identified and through repetitive scrutiny and comparison within the "conditions" for each definition, the concepts were categorised towards and reported as a review and classification framework (Pretorius, 2008a).

Finally a conceptual framework of the theory containing key insights for drivers and moderators was conceived and proposed. Each article was scrutinised for confirmation of concepts, additional concepts and differences (variance) under different conditions and contexts. The aim of the framework is to improve understanding of interrelationships between drivers and moderators of decline.

Eventually a list of key references, exceeding 200 articles, was assembled. The process of adding articles was never officially stopped, but drifted towards closure as no more "additional useful new information" came forth in accordance with the drivers suggested by the grounded theory research process. Key article contributions are reported to support the discussion of each driver and moderator, based on their apparent importance in the scientific literature. These were reported in more detail, and thereafter additional contributions were added to each category as they developed over time and contributed to or enhanced the understanding of variables. Grounded theory research includes the requirement for concepts to be repeatedly present in the new data (Corbin \& Strauss, 1990:7), thereby leading to the development of the proposed framework.

On completion the findings are discussed and explored for future research.

\section{Findings}

The findings of the research are reported as a conceptual framework of the "drivers" of business decline and are proposed to govern the thinking and reporting for the rest of the study. The proposed framework is actually the final result of the study process, but is reported at this early juncture as it contains the main driving forces and moderators of business decline. Some key references were cited with their contributions to support the key drivers and key variables that moderate how the drivers are manifested. The identified key drivers are my conceptions after application of the research process, and therefore citations to support the underlying thinking are given for confirmation.

The character of failure articles often leans towards some use of metaphors and paradigms; this could probably be ascribed to the non-quantitative nature, complexity and number of variables involved in ventures that experience decline. Authors tend to use metaphors to describe certain situational contingencies, people, styles and approach combinations. These combinations of configurations play a determining role in the causes of the decline, while the causes play the same role in the configurations.

Within the failure literature there appear specific drivers that alter the outcomes of the signs, causes, predictions, processes, strategies, cognitions and learning. These drivers are now explored.

\section{DRIVERS OF THE DECLINE AND FAILURE DOMAIN}

From the insights gathered in assessing the research articles, we find that there is a clear set of preconditions that governs each case, and therefore no two situations of decline can be exactly the same. These preconditions influence how decline is perceived, evaluated, learned from and eventually reacted on by a venture. Underlying the preconditions are the key drivers that caused the decline preconditions. 
Fundamental to the selection of the drivers is the concept of "governing principles", referring to such a driver's ability to influence both decline preconditions, other drivers and, potentially, moderators.

At first it was difficult to determine the progressive sequence for reporting these drivers; it appears to be a typical "chicken and egg - which comes first?" case. Each of the identified drivers is shown in Figure 1 and is elaborated on despite its being only the proverbial tip of the iceberg. Figure 1 shows three core drivers, three peripheral drivers and four moderators of venture decline. It also identifies some of the obvious proposed interrelations between the drivers and moderators.

\section{Defining the Core Constructs}

The study argument depends on three definitions. The definitions are given at this early juncture to assist readers to follow the arguments of the study, but finding the absolute definition is not the main aim of the study. The following definitions serve as working definitions.

Decline - A venture is in decline when its performance worsens (showing decreasing resource slack) over consecutive periods and it experiences distress in continuing operations. Decline is a natural precursor of the process to failure (Pretorius, 2009). It differs from failure in that a venture fails when it involuntarily becomes unable to attract new debt or equity funding to reverse decline; consequently, it cannot continue to operate under the current ownership and management. Failure is the endpoint at discontinuance (bankruptcy) and when it is reached, operations cease and judicial proceedings normally take effect.

Driver - In this text this refers to a key variable (the independent) with certain capabilities/strengths that strongly influence the decline (dependent variable) and may influence other variables (other independent variables). Thus the driver is a factor, such as rising interest rates, that may increase the possibility of a venture's defaulting on its loan repayment. Being identified as drivers implies that drivers have causal power over the observed variables. Two levels are identified in this study: core drivers and peripheral drivers.

Moderator - In this text this refers to a condition (the moderator) that will alter how one variable (the driver) may impact on decline and other variables (the independent variables under scrutiny). Under unforgiving industry conditions, for example, an interest rate increase has a more severe impact on a venture's ability to honour its loan than under industry growth conditions. Moderators therefore are responsible for creating variations in the drivers' effect on decline.

Figure 1: Drivers and moderators of business decline (Own compilation) 


\section{Drivers and moderators of decline}

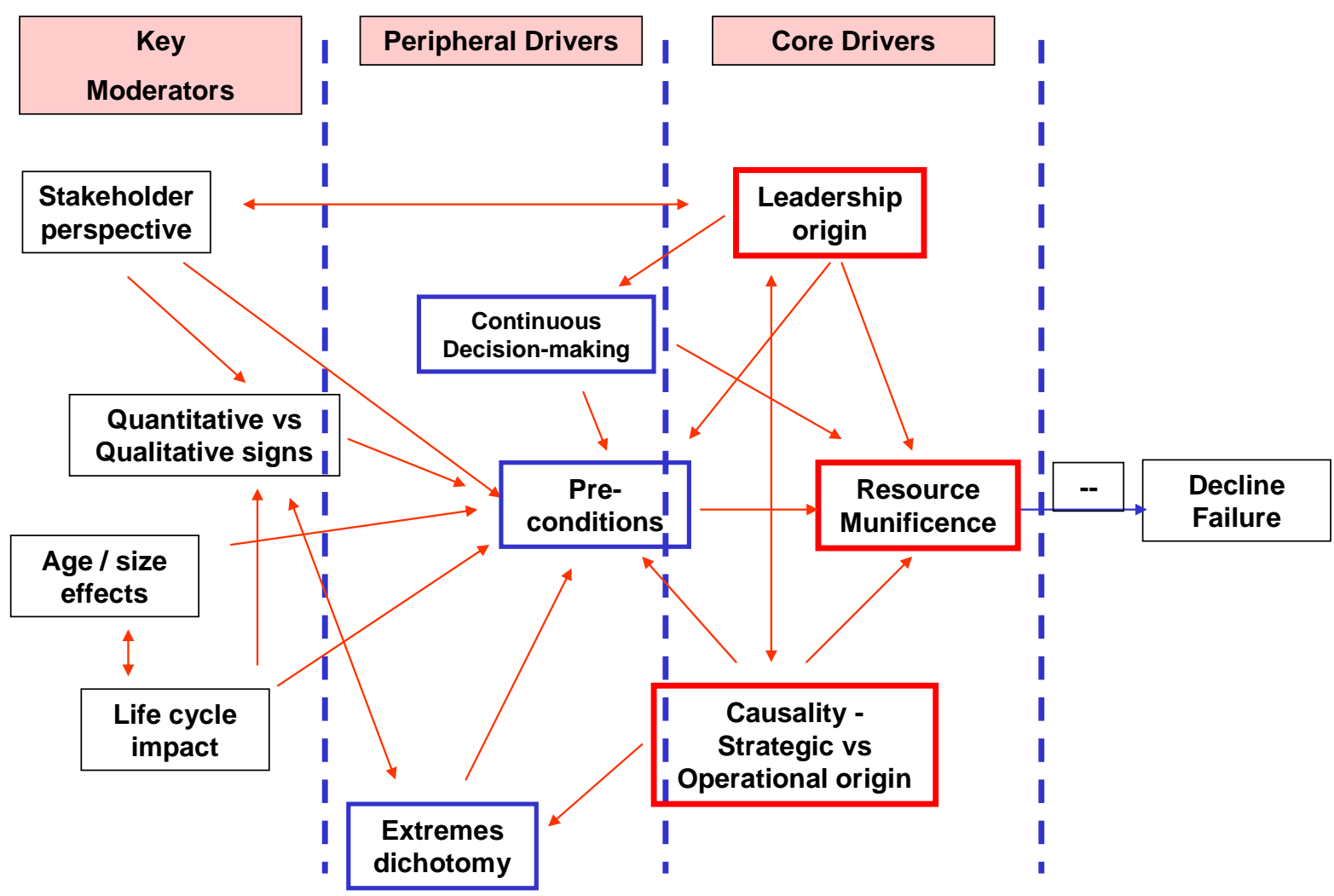

\section{Core Drivers of Business Decline}

The core drivers identified in this study are those variables that directly influence decline in a venture. Potentially they are the most influential variables, which can impact on other variables (peripheral drivers) most severely. Each is described within the limited space available.

Resource munificence as the dominant decline driver

Resource munificence suggests the abundance or absence of resources for the venture (Castrogiovanni, 1991). When resources are abundant, it is relatively easy for firms to survive and then develop the ability to pursue goals other than survival. When resources become scarce, however, competition intensifies, adversely affecting firm profitability and organisational slack.

Resource slack, or the lack of it, is arguably the key determinant of the severity of decline and the choice of turnaround strategies chosen in response. Also referred to as "organisation capital" (Levinthal, 1991:418), it varies depending on previous decisions, organisational learning and history and is central to the severity of the preconditions. Smith and Graves (2005:307) identify resource munificence, alternatively referred to as "level of free assets", as crucial in determining the success of turnaround interventions. Unabsorbed resource slack suggests increased ability to borrow funds and the ability to generate cash (liquidity) from the firm's assets (Barker \& Moné, 1998:1231), which gives firms the ability and time to respond through recovery strategies.

Levinthal (1991) refers to negative changing organisational capital as the most important determinant of firm mortality. Failure will happen if the minimum threshold for organisation capital is not met. The level of firm resources at the time of a turnaround attempt may affect the declining firm's capacity to implement strategic change. Maintaining adequate resources while responding to decline is often problematic because the decline process destroys firm resources over time (Barker \& Duhaime, 1997:20). Cressy (2006:104) further measures the role of "management human capital" as part of the resource capital, suggesting several aspects to the construct of resource munificence. Barker, Patterson \& Mueller (2001:239) add "reputational slack" as part of the resources available to the management of a venture. 
Environmental munificence (capacity to accommodate firms) has particular relevance for decline (Francis \& Desai, 2005:1202), as it determines the strategic options from which to choose during the turnaround situation. Environmental munificence plays an important role in the description of preconditions and the ability of a firm to recover from decline. The matching of resource and environmental munificence is part of the turnaround process.

Resource munificence, although often incorrectly thought of as only financial in origin, is influenced by the other core and peripheral drivers. Resource munificence appears at the heart of the failure domain, as shown in Figure 1. While all the drivers are important, they all impact on resource munificence, whether directly or indirectly, making resource munificence the main factor governing the failure domain (Pretorius, 2008b:4).

\section{Leadership as origin of decline as a driver}

Even the best strategy can fail if a corporation doesn't have a cadre of leaders with the right capabilities at the right levels of the organisation - Unknown

It is almost always management problems that lead to or are blamed for business failure (Chowdhury \& Lang, 1993:15, citing Boyle \& Desai, 1991, Edmunds, 1979, McGuire, 1976; Longenecker, Simoneti \& Sharkey, 1999:503) and this has not changed, since. Collard (2002:27) asks the question: "If the leaders who were in power while the company's position was allowed to deteriorate are still there, why should the lender believe that they would now be instrumental in correcting the situation?" Indeed, a question that brings perspective to the role of leadership. Barker et al $(2001: 237)$ report that replacement of the top management team is a core element in the turnaround process and coins it "TMT sweepout", where TMT refers to the top management team, be it leadership, directors, management or an individual in a smaller venture.

On the other hand, Barker and Duhaime (1997:13) report that turnarounds stem from top management's implementing cutback or retrenchment strategies that increase efficiency, and refer to retrenchment other than from top management as substantially reorienting the declining firm's strategy, thereby confirming that the choice is solely dependent on leadership decision making. By implication, it is about turning around previous decisions that resulted in the decline in the first place.

Chowdhury \& Lang (1993:9) further suggest, through threat-rigidity theory, that when a management team face a palpable threat (sudden crisis), they often freeze into inaction (experience cognitive rigidity), resulting in impaired decision making that propels failure. This threat-rigidity theory is confirmed by Mellahi (2005:264), while Barker and Moné (1998:1228) suggest that leadership under pressure will tend to pursue more mechanistic strategies. Alternatively, they suggest that when faced by gradual decline managers fail to detect or could even ignore and deny the signs and causes responsible for it, confirming Weitzel \& Jonsson's (1991) reference to the "blinded stage". This forestalls actions to counter such decline. It seems that both cases contain an element of leadership thinking at the origin of the action process required to turn around from decline.

Barker and Barr (2002:963) identify the impact of the top management team (TMT) as the key contributor to decline if they fail to change strategies. The TMT cognitions have an important impact on the decisions that influence the organisation's performance. These authors suggest that how the TMT perceives the causes of decline determines the extent of their recovery actions.

In a seminal work, Probst and Raisch (2005) report four elements associated with failure, one of which is leadership; and closely associated with leadership are the ability to change and the organisation's culture. While all three are "soft" issues, it seems that the origin of decline is the leadership's inability to adapt to change on the one hand and its inability to create the culture needed to support the strategy on the other. Cannon and Edmondson (2005:302) further suggest that managers have an incentive to dissociate themselves from failure because most organisations reward success and penalise failure. Thus, holding an executive or leadership position in an organisation does not imply an ability to acknowledge one's own failure.

Leadership is typically subject to heuristics and biases of management through overconfidence (Shepherd, 2005:125); escalation of commitment bias (Shepherd, 2005:129); risk perception; and misconceptions (Le Roux, Pretorius \& Millard, 2006:66). These biases influence leaders, which some researchers have termed "boiled frogs, drowned frogs and bullfrogs" (Bollen et al, 2005:7). 
There is sufficient evidence that leadership is at the core of all decline and creates preconditions, whether through leaders' ability or inability to respond to changing environments, chosen strategies and implementation actions or any decisions (non-actions and non-decisions) in response to the decline. Longenecker, Simonetti \& Sharkey (1999:503) confirm the leadership driver when they identify "failure at the top" as the main cause of failure. The literature on turnaround from decline abounds in examples of the appointment of new leadership when a firm has been in decline. Leadership's reactions, decisions, abilities and cognitions therefore directly and indirectly influence the resource munificence that governs preconditions for decline (Pretorius \& Holtzhauzen, 2008:5).

Causality (Strategic vs operational origin of decline) as a driver

The origin of the causes of decline is mostly categorised as strategic or operational in nature (Pearce \& Robbins, 1993:626). Commentators reason that it is easier for the business to respond to operational problems such as inefficiencies, unprofitable cost relationships, incorrect resource applications and managerial deficiencies, as these allow room to manoeuvre and the contributing factors are more visible. In contrast, strategic causes have to do with weak or wrong positioning in the market, technological changes that govern demand determinants and loss of competitive advantage by a venture - all highly susceptible to external influences not clearly visible to the decision making of leadership. Strategic factors have a close relationship with the external environment that forces the venture to respond to changes in its environment.

For a turnaround strategy to be effective in reversing decline, it has to address the declining firm's core problem (Barker \& Duhaime, 1997:14). A broad generalisation is therefore that strategically driven preconditions indicate a more severe decline, while preconditions originating from operational weaknesses indicate a less severe decline. The rationale appears to be that operational preconditions can be corrected with relative ease and expectation of success, while strategic preconditions require directional change and expectations associated with new venture creation. A poorly judged choice of new strategy by the leadership will therefore have a more severe impact on potential recovery than wrong operational decisions.

It therefore stands to reason that ineffective turnarounds often occur when management fails to successfully diagnose the causes of the firm's decline and responds inappropriately (for example by trying to increase efficiency when the firm's weak strategic position is the cause of the problem, or vice versa (Barker \& Duhaime, 1997:14).

Hence, the key drivers of decline are resource munificence, leadership and causality. Leaders respond to causality by adapting the resource application where they perceive the problem is located. If leaders are weak in their decision-making, resource munificence will deteriorate; or if leaders incorrectly "read" the origin of the decline, they can take the wrong decisions. The three core drivers are interrelated, as well as strongly influenced by other variables such as peripheral drivers and moderators.

\section{Peripheral Drivers of Decline}

The peripheral drivers referred to in this section are variables that directly influence the core drivers of resource munificence, leadership and causality of origin and indirectly influence decline.

Unique and non-static preconditions as a driver

Despite the existence of the core drivers associated with decline, each firm has a unique configuration of factors contributing to its decline. This makes selection of turnaround strategies dependent on the magnitude (severity, suddenness and urgency) of the specific conditions experienced by the declining firm, as well as the environmental munificence (Francis \& Desai, 2005:1205). Barker and Duhaime (1997:20) further confirm that a firm's history, culture, governance structure, diversity or size may increase or decrease a firm's (leadership) capacity to implement strategic change.

Unique preconditions as a driver depends on the rationale that decline (and failure) can rarely, if ever, be ascribed to one single cause or source but are usually part of a complex mix of interrelated causes hence the use of metaphors to describe such "sets of circumstances underlying the decline situation" (Pretorius, 2009:6). Often some of these causes are invisible to the observer and even masked by the management's own susceptibility to cognitive biases and previous exposure to the internal and external environments of the venture. Preconditions are deemed a driver because of their uniqueness, non-static nature and impact on all the other variables. Consider, for example, the different liabilities of newness, smallness and adolescence (Thornhill \& Amit, 2003:500; Henderson, 1999:281; Kale \& Arditi, 1998:459) as descriptors of different preconditions based on the configuration of causes leading to failure but through different processes. 
Preconditions therefore determine the decline, the uniqueness of the situation, the severity of the specific situation and the signs that are visible to the observer, but simultaneously depend on the origin of the cause (strategic versus operational, external versus internal) and respond to the leadership decisions and the nature and level of other variables.

Visibility of signs and causes appears to increase as the decline situation deteriorates and the venture progresses from performance, underperformance and decline to distress, crisis and eventual failure, which would each have its own set of preconditions. Visibility improves mainly because signs increase in number, extent of deviation and measurability. Preconditions also appear to linger and to build up in severity over time. A "trigger event" that may have a domino reaction sparks the decline and may mask the original causes of the situation and therefore the increase in visibility (Richardson, Nkwanko \& Richardson, 1994).

Preconditions have much to do with determining the severity of the decline, as the severity of the distressed state and the resource slack available ultimately determine the extent to which the declinestemming strategies are applied and succeed (Smith \& Graves, 2005:305). The longer the pattern of a firm's declining performance, the greater the certainty that it is actually in decline and not just suffering a temporary decline (Bruton, Ahlstrom \& Wan, 2003:527), while the severity and visibility of signs increase to assist management in identifying the problem.

Finally, preconditions are not static and will change due to many influences of external and internal variables (read moderators). Preconditions are therefore moderated by several factors (stage, duration of decline, severity of causal factors and others). While there are some generalisations, the unique conditions of the firm must therefore be considered when applying decisions of the turnaround process.

\section{Extremes dichotomy as a driver}

This driver refers mainly to causes of decline whenever they are present at extreme levels that deviate from the intermediate. The recent seminal work on failure by Probst and Raisch (2005) describes the logic of failure as dualistic in nature and the effects contributing to organisational failure. These authors postulate the factors as excessive versus stagnating growth; uncontrolled versus tentative change; autocratic versus weak leadership; and excessive versus absent success culture. Depending on the level of each factor, they describe the failure as resulting from either failure due to burnout syndrome or failure due to premature ageing syndrome. Their research indicates that burnout and premature ageing each require a different set of preconditions that may lead to that type of failure. The conclusion from this work is that decline is a result of deviations from the midpoint (where variables are balanced), depending on the combination of the four factors of growth (quantitative), and change, leadership and culture (all qualitative).

It is clear that decline relates largely to qualitative issues, which are inherently more difficult to define and measure objectively during research. Probst and Raisch (2005) indicate that leadership is more likely to contribute to failure when it is either weak or autocratic than balanced. Similarly, change contributes to failure if it is either uncontrolled or tentative, but not when balanced. Organisation culture contributes to failure if it is weak or excessively success driven compared with average culture. Therefore balance seems to be the key concept associated with success, while extreme deviation from the balanced position is associated with decline. Of course, not one factor determines the decline, but several in combination. At the same time there are several relationships that exist between the factors contributing to the preconditions.

Probst \& Raisch's (2005) study therefore establishes some important wisdom associated with decline: the dichotomy leading to unbalanced outcomes of factors leads to decline, so that decline is associated more with extremes than with the average levels of different variables; qualitative issues make up threequarters of the reasons for decline; and there are complex interrelationships between the variables that create the preconditions. .

Every decline situation therefore depends on its unique preconditions, the continuous decisions of leadership that influence the preconditions and whether the variable levels are extreme. So the peripheral drivers of decline are unique preconditions, continuous decisions and extremes dichotomy. Steyn Bruwer and Hamman (2006:17) also refer to the non-extremities that make prediction difficult. 


\section{Moderators}

Moderators, as defined earlier, refer to varying conditions that influence peripheral drivers (directly) and core drivers (indirectly), thereby moderating their effects on decline. These moderators include:

\section{Business life-cycle stage as a moderator}

This moderator is well acknowledged in the literature, given the importance it receives in research designs associated with decline and failure. Comparisons and inclusions of respondent companies are generally corrected for the effect of life-cycle stage. Turnaround strategies are specifically relevant for ventures in the decline phase of the venture life cycle, and the life cycle is a fundamental variable affecting business strategy (Anderson \& Zeithaml, 1984:8). At the same time, entrepreneurial (start-up phase) failure reports tend to focus more on the entrepreneur as a person as the reason for the venture failure, while failure in established businesses (mature or decline phases) appears to be more focused on external circumstances as reasons; thus it acts as a preconditions driver.

Causes and signs linked to the stage of life cycle vary greatly, as the stage partly determines the preconditions. Taggart (1995:296) suggests that the stage in the life cycle acts as a moderating variable through its influence on the value of market share position and the consequences of strategic decisions, as well as an enabling condition for opportunities and threats with strategic implications. The effect is that no homogeneous prescriptions are possible for declining firms. Often age is used as a proxy for the lifecycle stage, leading to similar effects on preconditions presaging decline and failure (Thornhill \& Amit 2003). Signals are less clear during the early phases of the decline (Lorange \& Nelson, 1987:43).

The impact of the business life cycle can be summarised:

- Life-cycle stage is a significant moderator of the signs and causes of decline, failure and ability to accurately predict potential future decline.

- Failure in a young business is more likely to be due to deficiencies in general management and financial management, while failure in an older business is more likely to be a function of external market forces and inability to respond to these changes.

- Resource munificence generally changes over the life cycle of a venture. Life-cycle stage moderates resource munificence, with slack increasing as ventures mature.

- Life-cycle stage is a significant moderator of the potential for successful recovery (turnaround).

- Leadership can become more experienced with maturity, but at the same time may become more blinded by previous success. Leaders may also tend to focus more on operational than strategic issues because of the lower visibility of internally focused strategies.

Levinthal (1991:401) postulates that the negative relationship between age and mortality rates is due to the fact that older surviving firms tend to be organisations that have been successful, and this prior success buffers them from subsequent selection pressures. He therefore evaluates the impact of the lifecycle stage and age through its impact on resource slack, confirming resource munificence as a driver. The life-cycle stage moderator is closely related to the age and size effect moderator discussed next.

Age and size effect as a moderator

Much of the work associated with the liabilities facing ventures closely represents the effect of venture age. Age as moderator is also closely related to the life-cycle stage moderator, despite being rather dissimilar. Key affects of age include its determination of resource munificence (availability) and control; legitimacy of the venture with different stakeholders; managerial development stage; learning and accumulated experience, and more. In this way, age normally impacts on the specific configuration of preconditions associated with different ages of ventures in decline. Typically, younger and older ventures differ as regards level of regulatory (policy) application, available finance for expansion, focus of managerial effort and others, leading to the different configurations. It has been reported that younger firms are more susceptible to leverage-induced factors, while older firms are more susceptible to factors originating in managerial apathy and inability to respond to change. In both cases the other category is not excluded.

Closely associated with size effect is the life-cycle stage of the venture, as growing older generally means movement through the life-cycle stages and becoming bigger. In Chowdhury and Lang (1993:12), businesses with less than a hundred staff are described as small, whereas in South Africa, for example, these would be described as medium or large business (South Africa, 1996). This suggests that definitions of size vary and should be considered, given the importance of size. Cowling and Westhead 
(1996:52) suggest that financiers should consider risk based on size, leading to small ventures paying higher interest rates, confirming they are more susceptible to failure than large businesses.

According to resource-based theory, large firms are more insulated and possess the stability to overcome adverse economic situations because of broader institutional systems. These characteristics can buffer an organisation's core from the effects of the environment (Francis \& Desai, 2005:1207). Levinthal (1991:401) suggests that age of the firm is rather a proxy for organisation capital (resource munificence), and that therefore there is no direct relationship between firm age and mortality.

Size of a venture has a profound effect on managerial factors and financial factors, both associated with causes of business failure (AI-Shaikth, 1998:75). Size is partly responsible for differences in the causes of failure in small compared with large businesses. Barker and Duhaime (1997:21) believe that greater size will increase the capacity of declining firms to enact strategic change in a turnaround attempt. Smith and Graves (2005:306) point out that there is empirical evidence for both positive and negative relationships between size and turnaround success. Some suggest smaller ventures are more adaptable and responsive, while large businesses in trouble have more "free assets" to buffer them during periods of distress.

Age and size usually moderate the resource munificence driver directly and can impact on the leadership driver indirectly, as they may moderate knowledge, experience, decision-making processes and more.

Quantitative/qualitative nature of causes and signs as a moderator

While many references report the quantitative aspects, especially finance and prediction based on different ratios associated with decline, there is a large portion of the failure literature that acknowledges qualitative content. What is further clear is that qualitative causes such as leadership, uncontrolled change, and organisation culture make up the largest contribution to decline and failure through the preconditions that are created (Probst \& Raisch, 2005).

Closely related to the quantitative versus qualitative nature of causes is the concept of "hard" and "soft" issues that contribute to decline. Inability to observe change in the environment that may lead to preconditions associated with decline and eventual failure is typically a soft issue, compared with finance and operations, which would be hard and measurable issues. Leadership as origin is therefore a human issue, while resource munificence contains both hard (finance and capacity) and soft issues (human capital) that are highlighted as core to decline. Often qualitative signs are first to appear, while measurement becomes possible only after some time has elapsed.

When implementing change (through turnaround), Higgens and McAllaster (2004:64) postulate that organisational changes and new strategies need to be bolstered by a supportive culture. Thus new cultural artefacts should be created through inclusion of key values and norms, myths and sagas, language systems and metaphors, symbols, rituals and ceremonies, and the use of physical surroundings. These artefacts (typically soft issues) can be used to help change the organisation's key values and norms to support the new structures, systems, processes, leadership style, staffing and resources during implementation of the new strategies. The nature of these artefacts confirms the importance of the softer issues, not only as part of the turnaround process but also as part of the preconditions in general.

The quantitative nature of variables suggests moderation of how resource munificence is perceived, leadership's decisions are interpreted and where causality is attributed; thus all three core drivers depend on the nature of preconditions.

\section{Stakeholder perspective as a moderator}

What the cause of decline is, who is responsible and how it should be rectified depends wholly on the stakeholders' perspective, thus revealing that the evaluation of decline and failure is dependent upon human cognitions and biases that are often far from those experiencing the decline.

Barker et al (2001:240) suggest that agency theory is based on the assumption that firm owners (principals) and their appointed managers (agents) have different interests. The same would be relevant for boards, as the principal, when appointing a turnaround management as agents who have different interests. A further example would be those with a financial interest in the venture, such as banks, who may respond inflexibly with penal charges and compound interest, while suppliers may demand cash payments from an already cash-strapped venture. Employees and unions, on the other hand, may respond with aggressive protectionism reactions and blame, making it harder for management to 
manoeuvre. In a similar vein, existing and new management will have greatly differing perceptions and therefore require "non-business" techniques to bring them together in one team. Therefore attribution theory will be significant in how causes and blame will be assigned.

\section{KEY OBSERVATIONS AND DISCUSSION}

The reading and evaluation of the literature led to some observations which in hindsight may appear to state the obvious but should be mentioned nevertheless.

Within the failure domain, metaphors are widely used, as has been mentioned in this study. Underlying this use of metaphors appears to be the fact that a large number of failure-related issues are vaguely definable circumstances and that the variables associated with decline and failures are qualitative in nature. Typically, the drivers of preconditions support this notion, as seen in the failure syndromes (Probst \& Raisch, 2005:90); frog metaphors (Richardson et al, 1994:9); and use of metaphorical decline stages (Weitzel \& Jonsson, 1991:7). Metaphors confirm the qualitative nature of causes and signs as a moderator, which makes it difficult to attribute decline to one variable only.

Secondly, severity of the preconditions tends to be subjectively measured, as very few objective measures are reported. Most objective measurements are associated with the prediction sub-domain, which requires comparative figures over several periods.

Thirdly, the central role of leadership (management) in the failure domain is substantial. Leadership's pivotal role takes effect through:

- leadership's skill and ability to perceive and make sense of overloads of information describing preconditions

- determination of strategies and decision making based upon leaders' perceptions and attributions

- applying biases (good or bad) when implementing their decisions or learning from failure.

- the direct impact of leadership on resource munificence, continuous decision making, preconditions and stakeholder perspective

The style of leadership and thinking preferences of the leaders are therefore antecedents of their decision-making and problem-solving abilities. Within the failure domain, leadership can be directly or indirectly associated with most causes of failure, albeit often in hindsight, and hence the "leader as origin" driver described earlier.

Fourthly, the dynamic nature of the unique preconditions depends heavily on the leadership decisions. By nature leadership is required to alter the context through decisions. Being aware of this impact on resource munificence is crucial for understanding the "new" preconditions as a result of the decisions. It becomes an iterative process.

Finally, evaluation of any preconditions depends on judgement by individuals. Such individuals are typically subject to cognitive biases and thinking preferences (Herrmann, 1996:43) that could be severely affected by the pressure of the decline situation. There are, therefore, few hard and fast rules to follow for decision making, given that each situation will probably be unique.

\section{Limitations of this Research}

Firstly the research methodology has some limitations, despite being quite an exciting process. At the outset there was no framework. During the collection of data (reading and rereading of articles) several frameworks developed which were repeatedly adapted to account for new insights. Consequently the final proposed framework is the conceptualisation of the author, which is by nature subject to own biases as well as experiences. Many iterations of the framework came to the fore as suggested by Corbin \& Strauss (1990) when they described the methodology.

The second limitation was probably the exclusion of some general works not readily reported in the scientific literature. However, these were mostly popular how-to-do books that were not necessarily driven by the underlying research focus required for this study.

Thirdly, the proposed framework tends to categorise related and unrelated issues into "boxes" to improve understanding through analysis. Using such a framework therefore also has some limitations, but it is believed that its advantages outweigh the limitations if the reader considers the high level of interrelatedness between the drivers and moderators described in this study. 


\section{Implications for Management}

Responding to decline means devising strategies. A prerequisite for successful strategising is clear understanding of the context through analysis. Management too readily blame decline on the recessionary environment and they do this mainly because they have no clear framework to give direction. This study could help practitioners to understand the complexity of the turnaround situation before they act, because the framework suggests a "logic" to explain the complex phenomenon. Secondly, those who are involved in the turnaround of declining ventures should realise the high-level interrelationships of drivers and moderators to successfully respond. The framework proposed in Figure 1 to some extent organises the complexity associated with decline. The framework then directs proceedings, especially when the continuous-decision-making driver plays its role by constantly changing the preconditions. Enhanced understanding of the context in which a turnaround situation arises makes the selection of strategies much more meaningful. The proposed framework assists the conceptualising of this improved understanding. For example, the framework acknowledges the unique preconditions of turnaround situations as a peripheral driver of decline.

\section{Directions for Future Research}

Future research should focus on turnaround strategies and practices as its unit of analysis. There is no framework for turnaround strategies that is comparable to the competitive strategies framework of Porter, for example. Such a framework is needed to direct selection of strategic practices, and would depend heavily on the core drivers as described in this study. One way to achieve this would be to do in-depth analysis of all practices used during turnarounds and then to categorise these practices into broad strategies, much as Akan et al (2006) did for Porter's strategies. The turnaround strategies proposed by Pretorius $(2008 \mathrm{~b})$ will also be challenged by such a process.

\section{CONCLUSIONS}

What set out as a study in the field of entrepreneurship ended in the heart of the business domain, covering more than failure and as such including elements of both the business and non-business environment. The origins and reach of decline and failure are extensive. As is characteristic of the grounded theory research approach, this indicated successful application of the research method, in which one sets out on a course whose destination is not clear on departure. The final adjustments to the framework happened at the very end (22 months into the project and much iteration later), when the key drivers were finally categorised into core drivers, peripheral drivers and moderators (Corbin \& Strauss, 1990:18).

The conceptual framework that is proposed highlights the high level of complexity during decline. The drivers and moderators of decline determine the eventual process and recovery strategies to be used when attempting to turn the business around. In-depth understanding mainly determines what processes and strategies will be decided on for recovery attempts.

While all stakeholders normally experience failure very negatively, decline appears to be much more positively received by some stakeholders, perhaps because of the potential for turning around from that course. Much of this depends on the learning that leaders take from their situations and their cognitive ability to interpret preconditions for decision making.

To sum up, several imperative drivers have been identified that influence the domain and are responsible for the variation in outcomes of decline. These are:

\section{Core drivers}

- Resource munificence, which determines a firm's ability to act, and is influenced by

- Leadership, which is the origin of decline in that all decline can be traced back to the ability or inability of the leadership to anticipate, recognise or respond to pending signs of eventual decline

- Causality (strategic versus operational origin) of decline, which governs the signs, preconditions and turnaround strategy options

\section{Peripheral drivers}

- The continuous decision driver postulates the influence of leader and management decisions on visibility of signs and the configuration of preconditions, which change continuously.

- Preconditions determine the severity and suddenness of decline and turnaround activities. 
- The extremes dichotomy driver suggests that decline is mostly associated with firms experiencing extreme configurations of factors (excessive versus slow growth and change, autocratic versus weak leadership, overly competitive versus non-competitive culture), rather than balanced configurations.

\section{Moderators that impact on the effects of drivers}

- The life-cycle stage and its influence on resource munificence affect how signs, preconditions, and turnaround processes will be manifested.

- The qualitative versus quantitative nature of causes and preconditions related to decline leads researchers to use metaphors and gestalts to assist them in explaining what those are. It appears that qualitative elements often weigh more heavily than the quantitative and measurable factors.

- $\quad$ The age and size effect suggests the impact of both age and size of firms on preconditions and turnaround options. This moderator depends heavily on resource-based theory.

- $\quad$ The stakeholder perspective suggests that how signs, causes and effects are perceived and attributed depends greatly on who the stakeholders are; variation is found between views of leadership, management (board, old versus new management), staff, financiers and others.

Knowledge of these drivers and moderators is important for practitioners, researchers and educators, as their effects need clear understanding if firms are to protect themselves from failure. 


\section{REFERENCES}

Akan, O., Allen, R.S., Helms, M.M. \& Spralls III, S.A. 2006. Critical tactics for implementing Porter's generic strategies. Journal of Business Strategy, 27(1): 43-53.

Al-Shaikth, F.N. 1998. Factors for small business failure in developing countries. Advances in Competitiveness Research, 6(1): 75-86.

Anderson, C.R. \& Zeithaml, C.P. 1984. Stage of the product life cycle, business strategy, and business performance. Academy of Management Journal, 27, March: 5-24.

Balcaen, S. \& Ooghe, H. 2005. 35 Years of studies on business failure: an overview of the classic statistical methodologies and their related problems. The British Accounting Review, Xx: 1-31.

Barker, V.L. III \& Barr, P.S. 2002. Linking top management attributions to strategic reorientation in declining firms attempting turnarounds. Journal of Business Research, 55: 963-976.

Barker, V.L. III \& Duhaime, I.M. 1997. Strategic change in the turnaround process: theory and empirical evidence. Strategic Management Journal, 18(1): 13-38.

Barker, V.L. III \& Moné, M.A. 1998. The mechanistic structure shift and strategic reorientation in declining firms attempting turnarounds. Human Relations, 51(10): 1227-1258.

Barker, V.L. III, Patterson, P.W. Jr. \& Mueller, G.C. 2001. Organisational causes and strategic consequences of the extent of top management team replacement during turnaround attempts. Journal of Management Studies, 38 (2): 235-269.

Barron, D.N.E., West, E. \& Hannan, M.T. 1994. A time to grow and a time to die. Growth and mortality of credit unions in New York City. American Journal of Sociology, 100: 381-421.

Bollen, L.H.H., Mertens, G.M.H., Meuwissen, R.H.G., Van Raak, J.J.F \& Schelleman, C. 2005. Classification and analysis of major European business failures. Report by Maastricht Accounting, Auditing and information Management Resesarch Center (MARC), Maastricht. October. www.fdewb.unimaas.nl/aim/downloads/pdf/MARC\%20rapport\%20total.pdf Accessed 14 December 2005.

Boyle, R.D. \& Desai, H.B., 1991. Turnaround strategies for small firms. Journal of Small Business Management, 29(3): 33-42.

Bruton, G.D., Ahlstrom, D. \& Wan, J.C.C. 2003. Turnaround in East Asian firms: evidence from ethnic overseas Chinese communities. Strategic Management Journal, 44(6): 519-540.

Cannon, M.D. \& Edmondson, A.C. 2005. Failing to learn and learning to fail (intelligently): how great organisations put failure to work to innovate and improve. Long Range Planning, 38: 299-319.

Castrogiovanni, G.J. 1991. Environmental munificence: a theoretical assessment. Academy of Management Review, 16(3): 542-565.

Chowdhury, S.D. \& Lang, J.R. 1993. Crisis, decline and turnaround: a test of competing hypotheses for short-term performance improvement in small firms. Journal of Small Business Management, 31(4): 8-17.

Collard, J.M. 2002. Steering clear of the brink: early warning signs pinpoint business troubles: changing leadership style to accomplish a turnaround. Journal of Private Equity, Fall: 25-31.

Corbin, J. \& Strauss, A. 1990. Grounded theory research: procedures, canons and evaluative criteria. Qualitative Sociology, 13(1) 3-21.

Cowling, M. \& Westhead, P. 1996. Bank lending decisions and small firms: does size matter? International Journal of Entrepreneurial Behaviour and Research, 2(2): 52-60.

Cressy, R. 2006. Why do most firms die young? Small Business Economics, 26: 103-116. 
Crutzen N. \& Van Caillie, D. 2007. The business failure process: towards an integrative model of the literature. Entrepreneurship and Innovation working paper. HEC Université de Liège. May. No 200705/02.

Cybinski, P. 2001. Description, explanation, prediction: the evaluation of bankruptcy studies. Managerial Finance, 27(4), November: 29-44.

De Castro, J.O., Alvarez, S.A., Blasick, J.D. \& Ortiz, M. 1997. An examination of the nature of business closings: are they really failures? Frontiers of Entrepreneurship Research. http://www.babson.edu/entrep/fer/papers97/decastro/. Accessed: 2005/03/10.

Francis, J.D. \& Desai, A.B. 2005. Situational and organisational determinants of turnaround. Management Decision, 9: 1203-1224.

Forbes, D.P. 1999. Cognitive approaches to new venture creation. International Journal of Management Reviews. 1(4): 415-439.

Henderson, A.D., 1999. Firm strategy and age dependence: A contingent view of the liabilities of newness, adolescence and obsolescence. Administrative Science Quarterly, 44: 281-314.

Higgens, J. M. \& McAllaster, C. 2004. If you want strategic change, don't forget to change your cultural artefacts. Journal of Change Management, 4(1): 63-73.

Herrmann, N. 1996. The whole brain business book. McGraw-Hill. New York.

Kale, S. \& Arditi, D. 1998. Business failures: liabilities of newness, adolescence, and smallness. Journal of Construction Engineering and Management, November/December: 458-464.

Le Roux, I., Pretorius, M. \& Millard, S.M. 2006. Entrepreneurial cognition and the decision to exploit a venture opportunity. South African Business Review, 10(10): 51-69.

Levinthal, D.A. 1991. Random walks and organisation mortality. Administrative Science Quarterly, 36: 397-420.

Longencker, C.O., Simoneti, J.L. \& Sharkey, T.W. 1999. Why organisations fail: the view from the frontline. Management Decision, 37(6): 503-513.

Lorange, P. \& Nelson, R.T. 1987. How to reorganize - and avoid - organisational decline. Sloan Management Review, Spring, 28(3): 41-46.

Mellahi, K. 2005. The dynamics of boards of directors in failing organisations, Long Range Planning, 38: 269-279.

Ooghe, H. \& De Prijcker, S. 2008. Failure processes and causes of company bankruptcy: a typology. Management Decision, 46(2): 223-242.

Pearce II, J.A. \& Robbins, D.K.1993. Towards improved theory and research in turnaround: Journal of Management, 19(3): 613-636.

Pretorius, M. 2008a. Critical variables of business failure: a review and classification framework. South African Journal of Economic and Management Sciences, 11(4): 408-430.

Pretorius, M. 2008b. When Porter's generic strategies are not enough: complementary strategies for turnaround situations. Journal of Business Strategy, 29(6): 19-28.

Pretorius, M. 2009. Defining business decline, failure and turnaround: a content analysis? South African Journal of Entrepreneurship and Small Business Management, 2(1):1-16.

Pretorius, M. \& Holtzhauzen, G.T.D. 2008. Critical variables of venture turnarounds: a liabilities approach. South African Business Review, 12(2): 87-107.

Probst, G. \& Raisch, S. 2005. Organizational crisis: the logic of failure. Academy of Management Executive, 19(1): 90-105. 
Richardson, B., Nwankwo, S. \& Richardson, S. 1994. Understanding the causes of business failure crisis: generic failure types: boiled frogs, drowned frogs, bullfrogs and tadpoles. Management Decision, 32(4): 9-22.

Robbins, D.K. \& Pearce II, J.A. 1992. Turnaround: retrenchment and recovery. Strategic Management Journal, 13(4): 287-309.

Sharma, D.S. 2001. The role of cash flow information in predicting corporate failure: the state of the literature. Managerial Finance, 27(4): 3-28.

Shepherd, D.A. 2003. Learning from business failure: propositions of grief recovery for the self-employed. Academy of Management Review, 28(2): 318-328.

Shepherd, D.A. 2005. The theoretical basis for my plenary speech about our successes and failures at research on business failure. Proceedings: [Conference on] Regional Frontiers of Entrepreneurial Research. Brisbane. February 123-134. Invited paper.

Shepherd, D.A., Wicklund, J. \& Haynie, J.M. 2007. Moving forward: balancing the financial and emotional costs of business failure. Journal of Business Venturing, 28(2): 318-328.

Smith, M. \& Graves, C. 2005. Corporate turnaround and financial distress. Managerial Auditing Journal, 20(3): 304-320.

South Africa. 1996. National Small Business Act, No 102 of 1996. Pretoria, Government Printer.

Steyn Bruwer, B.W. \& Hamman, W.D. 2006. Company failure in South Africa. Classification and prediction by means of recursive partitioning. South African Journal of Business Management, 37(4): 718.

Taggart, J.H. 1995. Strategy formulation in declining industries: a biology paradigm. Journal of Marketing Management, 11: 295-314.

Thornhill, S. \& Amit, R. 2003. Learning about failure: Bankruptcy, firm age, and the resource-based view. Organisational Science, 14(5), September-October: 497-509.

Weitzel, W.F. \& Jonsson, E. 1991. Decline in organisations: a literature integration and extension. Administrative Science Quarterly, 91, March: 91-109. 